\title{
Metaphor in Chemistry: An Examination of Chemical Metaphor [Preprint]
}

The history of definitions of metaphor is a history of hopeful efforts, none of which fully succeed in providing a satisfying answer to the question of what it is. Aristotle's original attempts to grapple with metaphor continue to inform (or infect) contemporary definitions of the term. "Metaphor consists in giving the thing a name that belongs to something else" [Aristotle Poetics 1457b5] on the basis of some kind of similarity. Everyone uses metaphor to communicate, but when aptly made, a metaphor is "strange" yet "sweet," and thus "most brings about the learning" ... but shaping good metaphors requires a special kind of genius that "cannot be learned from anyone else," Aristotle says [Aristotle Rhetoric 1410b]. Metaphor is a strange mix of the familiar and the unfamiliar, it is common and a mark of genius. For Aristotle a metaphor may connect two familiar things in unfamiliar ways such that the strangeness of it may be instructive. More commonly, metaphor is defined as that which associates an unfamiliar term with a familiar one in order to illuminate the former in light of its similarity with the latter. Aristotle's first definition seems banally simple: metaphor makes one thing stand for another.

The vagueness and generality of these definitions suggests an ineradicable circularity from the start: definitions of metaphor inevitably rely on metaphors. For example, the very notion of "standing" for something is itself a metaphor, one that has great significance in jurisprudence. The notions of familiarity, similarity, and their cognates, which lie at the heart of so many definitions of metaphor, are themselves metaphorical concepts. Metaphor is an oddly self-referential bit of language whose description can only ever be a performance of its meaning.

The following seven sections begin with a discussion of metaphor in science generally, then proceed to an examination of its role in chemical thinking in three contexts: the history and philosophy of chemistry, laboratory research practice, and chemical education. The chapter concludes with a section on the specifically chemical understanding of metaphor.

\section{Metaphor in Science}

The positive role of metaphor in science has been noted by philosophers, historians of chemistry ${ }^{1}$, science education researchers and educators ${ }^{2}$ where it has often been hailed as a descriptive and explanatory device that stimulates and shapes concept development. Several philosophers ${ }^{3}$ have noted the ubiquity of metaphor and proposed that all language is metaphorical. In his masterful treatment of that act of metaphoring, philosopher Kuang-Ming $\mathrm{Wu}$, presents an extensive cross-cultural hermeneutical survey of the variety of attempts to define metaphor. He finds all of them incomplete, though each one may be more or less helpful regarding some aspect. Not so helpful are attempts to treat metaphor as one among several figures of

\footnotetext{
1 T. Nummedal [2011] , Bensaude-Vincent and Stengers [1996], Newman and Principe [1998], Dobbs [2002], Merchant [1980], and others.

2 Jeppson, F [2013], Aubusson [2006], Tobin and Tippins[1996], Hofmann [1990] and others.

3 Black [1967], Cassirer [1953], Hesse [1966, 1988], Harre [1982], among others.
} 
speech, and subsequent attempts to split hairs among them. I follow $\mathrm{Wu}$ in his treatment of simile, metonymy and other non-literal forms, as different kinds of metaphoric activity, for in order to achieve the effects for which they are so often called upon, all non-literal forms of language rely on metaphoring. It is most beneficial, therefore, to see metaphor as a general form of communication activity, rather than as a specific linguistic formula that follows specific rules. ${ }^{4}$ Any attempt at hardening a definition of metaphor inevitably cracks up as novel forms of expression and understanding naturally emerge from cultural advancement.

Before moving on to discuss the specific case of metaphor in science, we may bring these general considerations of metaphor and language full circle in the context of Alfred North Whitehead's "fallacy of the perfect dictionary." Like other fallacies Whitehead introduces in the course of his philosophical reflections on science, this one points to the seemingly natural tendency of thought to capture the dynamism of concrete reality in static abstractions. One who commits the fallacy of the perfect dictionary misconceives both language and thought:

There is an insistent presupposition continually sterilizing philosophic thought. It is the belief, the very natural belief, that mankind has consciously entertained all the fundamental ideas which are applicable to its experience. Further it is held that human language, in single words or in phrases, explicitly expresses these ideas. I will term this presupposition, "The Fallacy of the Perfect Dictionary." [Whitehead 1938, 173]

Whitehead uses the fallacy to distinguish two philosophical attitudes: the "critical school" and the "speculative school:"

The critical school confines itself to verbal analysis within the limits of the dictionary. The speculative school appeals to direct insight, and endeavors to indicate its meanings by further appeal to situations which promote such specific insights. It then enlarges the dictionary. [Whitehead 1938, 173] Cultures advance, languages continually change, as does thought. In the midst of all of this change, the speculative school of philosophy finds in metaphor an engine of change, the source of linguistic and conceptual growth. In addition to those mentioned earlier, Bailer-Jones [2000, 2002], Ricouer [1981] and Miller [1986, 1996] are among philosophers who subscribe to the creative potential of metaphor in the science.

Metaphor, as Aristotle indicated, helps to make the unfamiliar familiar, but the current of meaning can flow both ways: the familiar can also be rendered unfamiliar enough to appear novel, strange and interesting. The dialectic of novelty and confirmation, so important to the Shannon definition of information, is also at play in the way that metaphor functions. How much a metaphor would lean towards confirmation or novelty, its signal-to-noise ratio in a given context, depends on a variety of complex factors. In this paper, we limit the contexts to those of education and research. Considered abstractly, education and research are polar opposites: research seeks novelty in the form of invention and discovery, while education strives to confirm the next generation of researchers by assuring their mastery of basic vocabularies, concepts and skills. But we must avoid mistaking these abstractions for

${ }^{4}$ This is, in fact, what Cassirer [1953] called "radical metaphor" and Kuhn [1977; 1979] referred to as "metaphor-like processes." This theme is discussed in depth in sections 5 and 6 below. 
concrete actualities. ${ }^{5}$ While education generally leans more toward confirmationoriented uses of metaphor, opportunities for student research may sometimes lead to breakthroughs. And whereas research is often geared toward the creation of novel metaphors in the process of model building, there are perhaps too many cases of research that merely confirms and solidifies the hold of a given approach. The creative potential of science is enhanced whenever metacognition is engaged in education or research, that is, when the function of metaphor in scientific thinking is acknowledged and, to whatever extent, understood and applied. ${ }^{6}$

Like Niels Bohr's horseshoe ${ }^{7}$, metaphor works whether or not one recognizes it as metaphor. And once it gains sufficient currency it is no longer considered metaphorical: it has made the transition from non-literal to literal. Commitment to a metaphor's literal "truth" has to last only as long as its ability to move inquiry forward; literal truth has no permanent status as literal and its lifespan is not known in advance of its employment. The creative power of metaphor is its liminality; this is also the source of its disruptive power. Paul Ricouer has noted that metaphor, like poetry, plays on the boundary between dogmatic commitment and speculative distance:

What is given to thought in this way by the 'tensional' truth of poetry is the primordial, most hidden dialectic--the dialectic that reigns between the experience of belonging as a whole and the power of distantiation that opens up the space of speculative thought. [1981, 371]

Metaphor enables the participation mystique of true dogma while maintaining a potential distance from the matter at hand (e.g., from the theoretical framework or model used in a given research project), thus providing a cognitive wedge that opens a space for speculation.

Self-reflexive awareness of metaphor renders its semantic frame labile - an important feature during times of conceptual fluctuation and growth... which come at an increasingly rapid pace for new areas of research. For Rom Harré the necessity of resorting to metaphor can be stated very simply:

We need metaphor because in some cases it is the only way to say what we mean since the existing semantic fields of current terminology referentially related to the subject in question are inadequate to our own thought. [Harré 1982, 95]

He considers metaphor to be an interventional tool rather than representational one. ${ }^{8}$ Metaphor's capacity to make a difference for a given inquiry is what matters, not its

\footnotetext{
5 The National Science Foundation and other science agencies have sought to dispel institutional tendencies to polarize the two modes of practice by issuing funding solicitations that call for integrative undergraduate science curricula. For example the NSF's Undergraduate Research Centers.

6 See Graves' [2005] treatment of this theme in section 4, and Bhushan and Rosenfeld's [1995] treatment in section 5 , below.

${ }^{7}$ As the story goes, a visiting physicist commented on a horseshoe hanging above the doorway of Bohr's country home, "Bohr, I didn't know you believed in such superstitions!" to which Bohr responded: "I don't, but I've heard that it works whether or not one believes in it."

8 Following Ian Hacking's [1983] Representing and Intervening.
} 
ability to accurately represent phenomena in various circumstances. The pragmatic aspect of metaphor puts its semantic lability to work to facilitate inquiry. Therefore, epistemological commitment to metaphor is justifiably flexible. A metaphor that is successfully put to use for a specific purpose may lose its usefulness, only to find it again if a new problem activates its multivalent potentials.

\section{The Metaphor at the Foundations of Chemistry: Defining Element}

A self-reflexive commitment to metaphor remains aware of its opportunities and limits, even when these have yet to be discovered with precision. This way of holding metaphor in mind makes particular sense in the context of chemistry. A significant case is found in the official International Union of Pure and Applied Chemistry (IUPAC) definition of chemical element, which, in an unusual turn, embodies a key duality ${ }^{9}$. On the one hand element is defined as atom, on the other hand as substance:

1. A species of atoms; all atoms with the same number of protons in the atomic nucleus.

2. A pure chemical substance composed of atoms with the same number of protons in the atomic nucleus. Sometimes this concept is called the elementary substance as distinct from the chemical element as defined under 1 , but mostly the term chemical element is used for both concepts.

[http://goldbook.iupac.org/C01022.html]

The relation between the two sub-definitions is similar to that which metaphor posits between any pair of subjects. No matter how subtle or great the difference between them, pairings of this kind open a space, as Ricouer noted, for speculation. A careful pairing of similarities and differences is, after all, the business of metaphor. An analogy can be drawn between metaphoric pairings and the pairing of wine and food: the pairing brings out latent flavors in both food and wine. In gustatory pairings flavors are amplified or diminished by combination. A metaphoric pairing is more complex in that it operates in the polysemic medium of language.

Ordinary language is by nature polysemic: individual words, not to mention phrases and statements, may admit of more than one meaning. Polysemic potential is further broadened by taking pragmatic and contextual considerations into account. Polysemy is an aspect of every language but scientific language strives to eliminate conceptual ambiguity by reducing the polysemic potential of key terms. One example of this is to be found in chemical nomenclature; the formal definition of terms by professional societies, such as IUPAC, is another.

In light of this fact, finding explicit bivalence in the official definition of 'chemical element,' at the very heart of chemistry, seems odd. The historical and disciplinary reasons behind it have been the topic of several articles in the philosophy of chemistry arena ${ }^{10}$. The definition originated with Fritz Paneth in 1931, in association with his successful work on the status of isotopes, which had been a vexing problem of early $20^{\text {th }}$ century chemistry.

${ }^{9} \mathrm{~A}$ full discussion of the development of this definition and its impact on chemical research and education appears section 6 of this chapter.

${ }^{10}$ See, among others, Earley [2009], Harre [2009], Mahootian [2013], Ruthenberg [2009], and Scerri [2000, 2005, 2009], and of course Paneth [1931/1962], who originated this definition. 
Paneth explicitly accounted for his bivalent definition and employed the metaphor of "oscillation" (Schwanken) by explicitly noting its function in chemical thinking. He introduced the metaphor in the historical context of the Boyle-Spinoza debate over nitre:

Boyle's statement that nitre 'consists' of volatile nitric acid and a solid residue shows just that oscillation [Schwanken] between the naiverealistic and the transcendental meanings of the terms which we exhibited above as particularly characteristic of the concept of element. [Paneth 2003, 136, emphasis original]

This historical illustration comes at the end of Paneth's two-part article (originally published in $1931^{11}$ ) whose purpose was to illustrate the epistemology of specifically chemical thinking. Though he does not label it as a metaphor, he takes advantage of the metaphoric potential of this dual-mode definition of chemical element. The selfreflexive use of metaphor in chemistry potentiates one's awareness of various frameworks of explanation, including disciplinary, conceptual, instrumental, etc. Paneth explicitly noted two frameworks - naïve realism and transcendental idealism - as the ones operative in the case of chemical element. I generalize Paneth's point in my (admittedly metaphoric) re-description of metaphor as that which enables and directs deliberate transitions between explanatory frames as needs arise in practical contexts of research, teaching, or engineering - naïve realism and transcendental idealism are only two possibilities among many [Mahootian 2013]. I claim that while such transitions are apparent in the history of any empirically grounded discipline, chemistry contains some of the clearest illustrations.

\section{Metaphor in the History of Chemistry}

With the growing general interest in metaphor there has been corresponding increase in the literature on metaphor in the philosophy of science. An excellent survey of the topic, by Daniela Bailer-Jones, appears in the Blackwell Guide to the Philosophy of Science. The closing line of her chapter provides a segue for discussing the history of chemistry, as it highlights the inextricable links between model, metaphor, practice and ordinary language. She notes that

beyond the commonalties of scientific models and metaphor already highlighted, there is one other: scientific models appear to be, contrary to past research traditions, as central in scientific practice for describing and communicating aspects of the empirical world as metaphors are in ordinary language. [Bailer-Jones 2002, 127] Bailer-Jones speculates analogically about this pair of pairs:

model : scientific practice : : metaphor : ordinary language

The analogy is not simple, as there are multiple interrelations between the four terms. Her main intent seems to be to illuminate the role of models in scientific practice as being similar to that of metaphor in ordinary language. However, because of the ambiguous role of ordinary language in scientific practice, and especially because of the function of metaphor in modeling (and of models in metaphoring), the analogy

\footnotetext{
${ }^{11}$ It was translated into English for publication in 1962 as "The epistemological status of the chemical concept of element" in British Journal of the Philosophy of Science. 13, 1-14 and144-160; it was reprinted in Foundations of Chemistry 5, 2003, 113-145.
} 
can readily be made to work in several directions at once, making the nexus of relations among the four more metaphorical than a straightforward (e.g. scientific) analogy should allow. Aristotle proposed that within metaphor the familiar term illuminates the unfamiliar, but one may as well assert that familiar and unfamiliar illuminate one another, occasionally trading places with sometimes surprising results $^{12}$. Such surprises often occur when familiar terms, models, instruments, etc., are applied to objects and domains beyond those in which and for which they were originally designed and intended.

Mary Jo Nye's conceptual history of chemistry, From Chemical Philosophy to Theoretical Chemistry, self-consciously traces the development of a specifically chemical approach to science, as distinct from physics. Nye briefly notes the relevance of metaphor throughout the history of chemistry and discusses specific examples in the $18^{\text {th }}$ and $19^{\text {th }}$ centuries ${ }^{13}$. She distinguishes "conventionalized metaphor," what $19^{\text {th }}$ century chemist Wurz referred to as "a way of expressing a fact rather than giving an explanation," from whimsical and playful descriptions, such as A. Laurent's 1854 descriptions of atoms on the "chase," in "copulation," and in "marriages of convenience." [Nye 1993, 78-80]. But all metaphor is a play on language and an alteration of everyday usage. While the extremes seem obviously distinct, the line that divides them is not easily discerned-certainly not during the period when such metaphors are suggested, for "as the problems change, so, often, does the standard that distinguishes a real scientific solution from a mere metaphysical speculation, word game, or mathematical play." [Kuhn 1962, 103]

The history of the concept of chemical affinity presents an interesting case in point. Nye demonstrates how this concept, originally considered explanatory, was later rejected in the light of other concepts and relevant new experimental data. The affinity concept reaches from its ancient origins in alchemy (like attracts like ${ }^{14}$ ), to its application in E. F. Geoffroy's 1718 table of chemical "rapports" for replacement reactions. The concept enjoyed new acceptance with H. Boerhaave's [1733] subsequent reinterpretation of affinity in terms of Newtonian forces of attraction and repulsion. Chemical affinity's gradual decline from mid- to late- $19^{\text {th }}$ century, culminated in its rejection by J. L. Meyer as merely fictional. Nevertheless, the concept played an important role in the development of thermodynamic models of chemical reaction, and in the classifications of chemical elements. Nye's foreclosure on the $19^{\text {th }}$ century history of affinity is somewhat premature, Meyer's objections notwithstanding. The concept enjoyed active use into the $20^{\text {th }}$ century: Van't Hoff

\footnotetext{
${ }^{12}$ Analytic philosopher, Max Black [1962] applied rhetoric theoretician I.A. Richards' interaction theory of metaphor in this manner. Kuang-Ming Wu's [2001] cross-cultural hermeneutic approach to metaphor affirms this point with examples from several contexts and languages.

${ }^{13}$ Nye completely excludes alchemy from her account-this is an important omission that follows in the steps of $19^{\text {th }}$ and early $20^{\text {th }}$ century historiography of science. I. Stengers and B. BensaudeVincent's History of Chemistry, published only a few years after Nye [1993], showed how fundamental concepts of chemistry, such as analysis, isolation and purification were developed to a high degree of sophistication. From the late 1990 s to the early 2000s, W. Newman and L. Principe provided a wealth of documentary evidence to support the inclusion of alchemy in the history of chemistry. Tara Nummedal discusses the versatility of alchemy's promotion of chemistry. ${ }^{14}$ The term "like attracts like" still enjoys broad usage ranging from matchmaking websites to titles and abstracts of research articles in academic journals of physics, chemistry and molecular biology.
} 
refers positively to affinity as a central link in his 1907 Nobel prize winning integration of gas laws and osmotic pressure. Stepping back from details such as this, Nye's narrative of the positive role metaphor plays in chemistry is generally on target:

The role of metaphor in defining a scientific object and suggesting a method of investigation is demonstrated in the history of the chemical discipline, both in the development of conventional definitions of the causes of chemical effects and in the working out of a system, which, by describing substances in the language of natural history, encouraged chemists to think about these objects along genealogical and morphological lines. [Nye 1993, 78; italics original]

The gain of epistemic access through metaphor is gradual. It occurs as a dialectical process that begins with epistemic commitment to a conceptual metaphor, which inevitably means commitment to some level of conceptual error. In the course of applying the metaphor in model-building [e.g. Harré 1982], we observe an alternating series of reifications and retreats from reification. In the centuries-long transition from chemical affinities to thermodynamics, we can trace the career of the mythical idea of nature as organism, to the metaphorical idea of "like attracts like" (which shaped sympathetic magic and alchemical thinking in pre-modern Europe), to $18^{\text {th }}$ century affinity tables, and finally to the gradual refinement of the idea of energy and energetic relationships among chemical compounds in various reaction environments. Such adjustments are made in the context of chemical practice: the more or less coordinated but always interdependent and mutual refinement of concepts, instruments, experimental design and observational targets. In this respect, contemporary studies of science in practice bear similarities with science education studies, as indicated below.

\section{Metaphor in a Solid State Physics Lab}

In this section, we focus on the uses of metaphor in a contemporary research lab. Heather Graves spent seven months studying the rhetoric of inquiry in a solid state physics lab with a seasoned researcher and his graduate students. She focused much of her time on research about amorphous semiconductors, specifically, persistent photoconductivity. What Graves learned about the function of metaphor in this context can be readily transferred to our study of chemistry.

Rhetoric In(to) Science: Style as Invention in Inquiry [Graves 2005], argues that since the time of Robert Boyle, and culminating in the work of Joseph Priestly, science has appropriated the rhetoric of invention theory into scientific method. One of the founders of experimental method, Boyle considered it important to communicate what and how he thought about his experiments, taking pains to recreate his thinking in the mind of his reader (recall Whitehead's characterization of speculative philosophers, in section 1 , above). He made this an explicit goal of his style of writing. Both he and Priestly held metaphor and analogy to be far more than merely decorative or persuasive: both saw metaphor as a means of "meditating" and "reflecting" upon ideas. Both considered metaphor as a chief means of associating and extending ideas by "transferring similarities" from one domain to another. This 
transference is explicitly discussed by Priestly in both his scientific and religious writings. [Graves 2005, 75]

Graves reports that her interactions with lab director Edward MacDonald [a pseudonym] stimulated him to do his science "aloud." This provided her with several opportunities to record the development of analogies and metaphors. She noted varying degrees of success in the application of metaphors and analogies to the task of interpreting experimental data. Normally, MacDonald would sit at the computer, revising and deleting, until he had the most unambiguous text for the purpose of communicating research findings. Graves' in-depth analysis of several episodes of experimental work by MacDonald and his research team, demonstrates the epistemic contribution of rhetoric in a number of instances. Most of her observations pertain to the re-interpretation of experimental findings in the course of preparing an article draft for publication. She shows how such discussions were often coupled with refinements to the lab's research strategy.

To conclude this section I note that Graves' discussion of the use of analogy, metaphor and metonymy ${ }^{15}$ in the research process is consistent with previous work in this area; while there are several instances to draw upon, only two will be noted.

The first instance confirms Mary Hesse's [1980] understanding of the function of analogy in science research: MacDonald first predicts and later confirms a particular phenomenon. The analogy he draws between hoodoos and an amorphous silicon nitride superlattice cross-section, "establishes three known terms with the purpose of predicting a fourth unknown term." [Graves 2005, 102].

In contrast with those who focus on the discursive qualities of science but not its practice, and those who focus on its practice but not on its rhetoric, Graves focuses on the role of rhetoric in the process of inquiry.[Graves 2002, 2] In so doing, she clarifies one aspect of the role of metaphor in concept formation in and through the process of grappling with data and models. The key link in this process is the act of invention wherein novelty is introduced to the practice of science by "mangling" data, theory and interpretation, as Andrew Pickering calls it. The "mangle of practice,"16 characterizes the concrete practice of lab bench science. As a quantum physicist, Pickering's [1984] research experience with quarks led him to reflect on the practice of science and the articulation of the mangle of practice described above. He summarizes the process:

modeling has an important real-time structure, with contours of cultural extension being determined by the emergence of resistances, and by the success or failure of 'accommodations' to resistance... This temporal structuring of practice as a dialectic of resistance and accommodation is, in the first instance, what I have come to call the mangle of practice. [Pickering 1995, xi]

\footnotetext{
15 Graves focuses more of her analysis on the lab's use of metonyms than on metaphors, however, the case has been made in section 1 above, that the various genera of non-literal usages of language actually function metaphorically, even if they are not identical in form to metaphors. Kuhn's [1977, 1979] and Cassirer's [1953] discussions of this idea are found in sections 5 and 6, below.

16 Pickering's seemingly odd choice of this term harks back to old-time clothes washing machines which had no spin cycle. Instead, wet clothing were put through the ringer and the resulting "mangle" consisted of diverse items of damp clothing pressed into a single, flat, apparently continuous plank.
} 
At various points in the research cycle, as researchers inevitably encounter results that are somewhat different than expected, they will alter the ceteris paribus conditions, the explanatory model, the selection of relevant theories, the boundary conditions of the phenomena under scrutiny, even the standard operating procedures of their laboratory equipment. Essentially anything, whether theoretical or instrumental, that can be bent to its near-breaking point will be bent; theory and model will be made to accommodate instruments and experiment design and vice versa, until expectations of acceptable experimental outcomes closely match actual experimental outcomes.

Graves' analysis of the rhetoric of invention in MacDonald's descriptions of his research team's model-building efforts is consistent with Pickering's understanding of the mangle of practice. MacDonald and his co-workers undertook to modify standard solid state physics models in order to fit the diverse experimental settings for which they were not originally designed; in some cases, modifications were stimulated by peer-review comments accompanying the rejection of their article for publication in a journal.

\section{Metaphor in Chemistry Education}

Nalini Bhushan and Stuart Rosenfeld's 1995 article, "Metaphorical Models in Chemistry," offers an analysis of metaphor in reference to scientific modeling in the service of specific pedagogy in chemical education. The authors cite James Hofmann's [1990] study of "How the Models of Chemistry Vie," a play on Nancy Cartwright's [1983] How the Laws of Physics Lie. Hoffmann distinguishes two functions of models in chemistry as "the culmination of phenomenology and the commencement of explanation" [Hofmann 1990, 406]. The former offers "specific causal scenarios," while the latter presents "unifying explanatory formalisms." Oddly, Bhushan and Rosenfeld substitute these functions with the not exactly equivalent pairing of "predictive" vs. "insightful." The contrast of causal scenarios from predictive ones, and explanatory formalisms from insightful ones requires clarification. In the context of their discussion, Bhushan and Rosenfeld note that "[a] working view for students might be that models should be seen as tools for prediction and correlation but that one should remain aware of their metaphorical standing." [Bhushan, Rosenfeld 1995, 579]

An understanding of the "standing" of models as "metaphorical" is sufficient to arm the student against swallowing the model whole, as it were, and taking it as literal truth. Bhushan and Rosenfeld consider this to be good pedagogy. Furthermore, they note that both aspects, prediction and insight, are metaphorical, since it is "not so odd to view computational models as metaphorical" [581]. Though they don't say so explicitly, their pedagogy elucidates the metaphorical nature of models in order to disabuse students from habitually thinking of models as representations. Bhushan and Rosenfeld's pedagogical ideals seem consistent with thinking about models as interventions rather than literal descriptions. Although the authors conclude their article with the following passage, it is unclear whether, in the final sentence, they are using the term model in a metaphorical way:

Our own lack of attention to the metaphorical nature of a particular model can blind us as teachers to certain misunderstandings of students. As we use models in teaching, it may be important to recognize that the leading edge, and perhaps the most important part of the model for students, is the metaphor. 
Indeed, we might say that where we use models in our teaching, the

metaphor is the currency of the teacher-student transaction. [582]

Indeed, they introduce a metaphor, i.e., the currency of a transaction, to characterize their own use of metaphor. This would seem to reinforce Bailer-Jones' closing statement which exhorts us to consider whether model may be as ubiquitous in science as metaphor is acknowledged to be in language. Furthermore, Bhushan and Rosenfeld's currency metaphor makes explicit a value orientation that Mary Hesse asserted as a necessary part of metaphor. In Hesse's words, [MISSING WORD] is an "evaluative interpretation," i.e., one that takes a "proper stance" toward the phenomenon in question and thus "implies that metaphor is concerned with action as well as description." [Hesse 1988, 14] This is also consistent with Thomas Kuhn's remarks on metaphor and science education.

In his later writings, Kuhn highlights the work of metaphor in the education of naïve science students as a case of changing "seeing" into "seeing as," for example, seeing certain spots in a microscope as microorganisms. Making invisibles visible also makes other visibles invisible in order to clear the way, so to speak, toward the newly identified target. Kuhn takes metaphor to be "essentially a higher-level of the process by which ostention enters into the establishment of reference for natural kind terms." [Kuhn 1979, 537] His "Second Thoughts on Paradigms," deal with the related question, "How do scientists attach symbolic expressions to nature?" Kuhn couches his answer in terms of the activity of "recognizing similarity sets," or transforming seeing into seeing-as. To successfully solve the problems in a science textbook requires just this ability. "The student discovers a way to see his problem as like a problem he has already encountered. Once that likeness has been seen, only manipulative difficulties remain." [Kuhn 1977, 470] Science education, according to Kuhn, involves conveying to the student a body of standard examples ("exemplars" or paradigms). "Acquiring an arsenal of exemplars, just as much as learning symbolic generalizations, is integral to the process by which a student gains access to the cognitive achievements of his disciplinary group." [Kuhn 1977, 471] These exemplars are often in the form of specific problems and their solutions which have been raised from the myriad situations encountered in naive experience. There are several standard metaphors in these statements that might attract the usual kinds of attention (inquiry as a war that requires an "arsenal") but I would direct our attention to a deeper layer: attachment, as in the "attachment of symbolic expressions to nature." [Kuhn 1977, 467] The process of reference-fixing, or "dubbing," is what Kuhn calls a "metaphor-like process," which he considers more fundamental and less obvious than the similar process operative in metaphor. "Metaphor plays an essential role establishing links between scientific language and the world." [Kuhn 1979, 539, emphasis added]

The establishment of "similarity sets" is a specialty of the metaphoric mode of discourse. Kuhn notes that "[it] is sometimes (perhaps always) revealing to view metaphor as creating or calling forth the similarities upon which its function depends. With that position I very much agree."[Kuhn 1979, 533] The process of scientific education, as well as that of scientific discovery and invention, involves just this kind of mental transmutation: a creation of categories by means of elevating certain impressions from the realm of naïve realism into the realm of scientific significance. 
Kuhn approaches this conception, finally dropping the distinction between metaphor and metaphor-like processes, for the sake of brevity:

'metaphor' refers to all those processes in which the juxtaposition either of terms or of concrete examples calls forth a network of similarities which help to determine the way in which language attaches to the world. [Kuhn 1979, 539 emphasis added]

Whether or not Kuhn is aware of this (and there is no indication of this in his writing), the idea of any attachment of language to the world is metaphorical. Ernst Cassirer, on the other hand makes this an explicit claim that lies at the basis of his Philosophy of Symbolic Forms. For Cassirer, the very act of speech, the act of attaching thought to a medium that is fundamentally different from thought (i.e., sound) is itself an embodiment of metaphor, as one thing is made to stand for another. Cassirer also notes that "radical" metaphors don't merely point out similarities and dissimilarities, they institute them. This is one manner in which metaphorical commitment has practical, even material impact.

The question of how conceptual categories are first instituted is one that is relevant to both research and education. A recent study of the use of metaphor in science by education researcher, Frederik Jeppsson and his co authors ${ }^{17}$ makes three key claims about the role of conceptual metaphor (CM) in scientific problem solving. In the course of making these claims, the authors review much of the literature of education theory on this topic and affirm a key point that is of interest to my analysis: the question of whether experts and novices share conceptual strategies, or employ distinct ones in solving scientific problems. Until recently the latter position ${ }^{18}$ was favored, but recent evidence arising from education research has provided support to the former position, represented in the work of Gupta, et al. For example, according to Gupta, novice and expert use similar conceptual resources, but in addition to having a broader variety of CMs, experts have greater flexibility with regard to the ones they use. In their studies, Gupta, et al, show that both expert and novice use basic CMs drawn from everyday experience, often reifying concepts or processes, for example, treating them as material substances in the course of reasoning about them. Whatever may be the degree to which experts use concrete metaphors instead of the "abstract" and "constraint-based"19 ones specific to a given disciplinary discourse, they switch seamlessly between CMs. The switch may occur between different phases of the research process, and/or between doing research and teaching. This finding confirms the liminality of metaphor discussed in sec. 1, above.

Gupta found that besides reifying concepts as material substance, researchers also engaged in metaphorical identification with and projection of agency. These tendencies were exemplified in Graves' observation of MacDonald's researchers. These tendencies are consistent with the definition of metaphor as a rhetorical form that introduces something unfamiliar in terms of something familiar. There are other compelling reasons for favoring Jeppsson's presentation of the continuity between expert and novice. The history of science is full of stories about how the expert's

\footnotetext{
${ }^{17}$ Fredrik Jeppsson, Jesper Haglund , Tamer G. Amin \& Helge Strmdahl [2013] Exploring the Use of Conceptual Metaphors in Solving Problems on Entropy, Journal of the Learning Sciences, 22:1, 70-120. 18 represented by Chi and Slotta [Jeppsson 2013, 72]

19 Jeppsson, et al $[2013,72]$ quoting Chi \& Slotta, 1993.
} 
mentality mingles with that of the novice in the initial framing of an incorrect model. Thompson's plum pudding model and Rutherford's solar system model of the atom were later refined by others in the course of trying to apply them in theory building and experimental design.

Ernst Cassirer's neo-Kantian epistemology grounds his Philosophy of Symbolic $F_{o r m s}{ }^{20}$ on the continuity between different modes of symbolic thinking, with mythic and scientific thinking occupying the extremes. Rather than summarize its argument here, I note that some of his key conclusions are supportive of the continuity thesis developed by Gupta et al, and incorporated in the claims of Jeppsson, et al. The following excerpt from Cassirer's chapter on "The Power of Metaphor" suffices to show the consistency of his analysis with what Jeppsson et al. note as the crucial feature of expert knowledge: flexibility with respect to choices among conceptual metaphors, and a metacognitive grasp of such decision-making and implementation. Cassirer talks about the final stages in the development of thought, wherein selfconsciousness is characterized by self-possession. At its final stages of development, thought is no longer compelled by concrete aspects of imagination that shape the two instruments that co-evolved, and thus co-determine one another, namely, language and myth.

Word and mythic image, which once confronted the human mind as hard realistic powers, have now cast off all reality and effectuality; they have become a light, bright ether in which the spirit can move without let or hindrance. This liberation is achieved not because the mind throws aside the sensuous forms of word and image, but in that it uses them both as organs of its own, and thereby recognizes them for what they really are: forms of its own self-revelation. [Cassirer 1946, 99]

The idea of the scientific mind using word and image as "organs of its own...self-revelation" is especially important: in scientific problem solving experts consciously choose to use materialistic (and other concrete) metaphors drawn from daily life. That is, for as long as it is useful, the expert knowingly acts as if the metaphor is literal, then switches to a more abstract metaphor for which there is no experiential basis, or even runs contrary to the expectations of naïve experience. On such occasions, the expert's recourse to seamlessly juxtaposing qualitative and quantitative thinking whenever possible (ala Jeppsson), enables powerful inferential moves facilitated by a range of mathematical formulae. The whole range of modes, from concrete metaphor to abstract mathematical relation, is used in various stages of scientific inquiry, whether the inquirer is novice or expert. The differences between them emerge with the sophistication of abstractions, on the one hand, and the facility of moving between abstraction and concreteness when need and opportunity arise.

\section{A Chemical Concept of Metaphor: Reconsidering the Chemical Element}

Let us return at last to the definition of chemical element, as established by

20 In 3 volumes [1925-29] Yale University Press. Cassirer draws on a broad multidisciplinary pool of evidence from human, social and physical science of the mid-twentieth century. 
IUPAC. I consider the most intriguing part of Paneth's formulation of this concept of element to be the necessity of schwanken, the oscillation ${ }^{21}$ between the abstract transcendental and the concrete naive realist view. In an earlier section of this chapter we noted that this definition suspends the concept of element in a space of speculation between the two poles in much the same way that metaphor suspends judgment between intersecting sets of alternative meanings. Where definitions are intended to attenuate the inherent polysemy of language, metaphor activates multiple sets. The unique feature of the IUPAC definition, seen below, is that it wants it both ways: the distinction is spelled out in the second definition but withdrawn by the end:

1. A species of atoms; all atoms with the same number of protons in the atomic nucleus.

2. A pure chemical substance composed of atoms with the same number of protons in the atomic nucleus. Sometimes this concept is called the elementary substance as distinct from the chemical element as defined under 1, but mostly the term chemical element is used for both concepts.

[http://goldbook.iupac.org/C01022.html]

It is interesting that both definitions of chemical element are deemed necessary, that neither can be reduced to its partner, nor can both be reduced to a simpler definition. Two definitions of element are brought together as partner terms in a metaphor. There is an irreducible space between them and this is what metaphor posits between similars. The relation between the definitions is not only semantic or syntactic, it is pragmatic: it does what Hesse refers to as taking a "stance" on the world. The relational space between the metaphorical partners draws on potential domains of application, potential relevance-determining contexts. Every metaphor must be generated in the service of a particular experiment that is specified by the experimenter's research design, instruments and ceteris paribus conditions. The chemist's practice is also shaped by existing theoretical models that more or less fit the experiment design, materials, and collected data. There is always a gap of some unknown size, a space between the general conditions for the application of existing models and the actual conditions, between the generalities of theories and best practices, and the particulars of the experiment at hand in the present moment.

The space of metaphor, the space between the familiar and the unfamiliar, is filled with the "light, bright ether" that Cassirer speaks of (see previous section). It is the same space indicated by Kuhn's questions, "How does mathematics attach to the world?", "How do our concepts attach to the world?" and, "How does language attach to things?" Though devils lay in wait in the particular details, at root the answer is the same: the attachment is metaphorical. But what does that mean? Cassirer's idea of radical metaphor captures this question in its primal instance, i.e., the first utterance of a word:

Indeed, even the most primitive verbal utterance requires the transmutation of a certain cognitive or emotive experience into sound, i.e., into a medium that

\footnotetext{
${ }^{21}$ Mahootian, F. 2013 "Paneth's epistemology of chemical elements in light of Kant's Opus postumum." Foundations of Chemistry 15:171-184.
} 
is foreign to the experience, and even quite disparate; even as the simplest mythical form can arise only by virtue of a transformation which removes a certain impression from the realm of the ordinary, the everyday and profane, and lifts it to the level of the "holy," the sphere of mythico-religious "significance." This involves not merely a transference, but a real $\mu \varepsilon \tau \alpha \beta \alpha \sigma \iota \sigma \varepsilon \iota \sigma \alpha \lambda \lambda \sigma \gamma \varepsilon v o \sigma$, in fact, it is not only a transition to another category, but actually the creation of the category itself. [Cassirer 1923/1953, 87-8]

Cassirer's reconfigures the discussion of metaphor in this passage. His thoughts about the creativity of what he calls "genuine radical metaphor" closely resemble what Whitehead, Kuhn, Harre and Hesse have noted as the creative function, specifically the knowledge creation function of metaphor. This conception goes beyond the standard ways of mapping the terms, or concepts, of an analogy or analyzing a metaphor's transference of properties between categories. ${ }^{22}$ Interesting, fruitful and popular as semantic- and logic-mapping exercises are, we have something new here. Cassirer draws attention to radical metaphor's creation of new categories.

In seeking radical metaphor in the human urge toward symbolic expression, Cassirer found the unbridgeable space between experience and language. This gap is the source and scene of radical metaphor. In this "empty" space, to which neither language nor thought can lay claim, is the originary experience that Whitehead was so interested in. The creativity that an individual is capable of, the true novelty of the as-yet-unspoken, lurks in the "wilds of so-called 'empty space"" [Whitehead 1929, 199]. By "empty" Whitehead meant space that is empty of the ordering activity of (human and non-human) agents; this "interstitial" space is where he locates life and consciousness. While both life and consciousness rely on (more or less) stable chemical cycles they do not merely replicate these patterns but take advantage of the order and energy they generate and maintain. This is where Whitehead sought the ultimate potential for spontaneity [Whitehead 1929, 105-6].

Just as the spontaneity and novelty of life and consciousness are dependent on the regularity and stability of physics and chemistry, so too thought relies upon the stability of language and cultural norms. Thought is partly dependent and constrained by language but it grows and thrives by altering these constraints through the creation of new words that redefining the old by recasting them in connection with other players, other contexts of interaction. Scientific knowledge is necessarily constrained by vast networks of vocabularies, categories, procedures, algorithms, models, instrument, data, etc. Nevertheless, knowledge continues to grow because scientists design experimental conditions and induce data to which the network of the known may not apply very well, or at all. Whether or not these conditions are brought about deliberately, on such occasions scientists must improvise activities based on partially applicable existing models. Improvisation takes the form of metaphorical and instrumental incursions into the unknown. Boyle knew this, and sees this as part of normal life in a research lab: metaphors, analogies and models are retained only so long as they work to achieve well-articulated goals identified by the

22 As found for example in Lakoff, G., and Johnson [2008]. 
changing norms, standards and challenges of disciplinary cultures. MacDonald

Publication a central goal that encapsulates past research, secures the position of researchers and propagates future research. Publication within a scientific discipline is more than a simple record of events, facts, materials, methods and so on. It is a complex interweaving of data, interpretation, rhetoric, style... it is an act as well as a fact. Moreover, chemistry, and a few other allied sciences, actually create the objects of their discipline. In such fields, the role of rhetoric is sometimes heightened. An example from Graves' account of MacDonald's publication process bears this point out.

Graves recounts that the original draft of the article was rejected and reviewers offered comments, suggestions and requirements for additional data. Rather than running the experiment again in order to obtain new data, MacDonald presented a different selection of data previously gathered. MacDonald coupled his additional data with citations of data and theories about the photoconductivity of similar amorphous semiconductors, containing varying amounts of nitrogen. Graves analyzed the manner in which MacDonald used metonyms to make claims about structure on the basis of the semiconductor's behavior under various conditions ${ }^{23}$. In this case, which is by no means uncommon in scientific literature, select processes were made to stand for structures whose existence the peer reviewer initially contested but finally accepted. The phenomena and actual entity under discussion, i.e., photoconductivity in an amorphous semiconductor, did not change between the prepublication draft and the published version: in both phases, MacDonald tried to establish the existence of a specific kind of structure for the photoconductive thin film they had generated using the IBAD process in their lab. Graves analyzes shifts in reasoning and presentation of ideas surrounding the manufacture and testing of the a-SiN ${ }_{x}$. Furthermore she analyzed stages of the research team's response to the reviewer's comments. Graves' summary of the process asserts that the team pursued a cyclical process of collecting measurements..., conjecturing about the process(es) that yielded those measurements, and pursuing various explanations for the physical structure suggested by the combination of data and theory. Through this complex process, they derived evidence of the existence of particular characteristics such as structural properties or flaws in the a-SiN ${ }_{x}$. However, the movement, back and forth between real entities and proposed theoretical concepts and processes often blurred the boundary between what was real and what was theoretical. [Graves 2005, 193] Graves here conflates "real" with "data." This conflation indicates her tacit commitment to a metaphysical realism that is at odds with the various alternatives to realism she ably discusses in her book. Similarly, the "blurring of the boundary" refers to a hard boundary that is only there if one accepts the "standard view" philosophy of science distinctions between theoretical and empirical. Similarly, her invocation of boundary indicates buy-in to the demarcation of the standard view's "context of justification" vs "context of discovery" distinction, a distinction whose absoluteness was successfully challenged over 50 years ago by philosophers and

23 Metonymy is a specific kind of metaphor that makes a part, or aspect, stand for the whole e.g., saying "friends, Romans, countrymen, lend me your ears." 
sociologists of science.

There is a significant difference between theory and data, but it is better characterized not as blurring, but as interaction: a mutual interdependence that varies according to discipline, experimental setting and context. Decades of research on the actual practice of science has sharpened the focus on the relationship between data and theory: the relationship is a blur to the extent players have not articulated the dynamics of their interaction. Neither Graves nor MacDonald is a philosopher, so their use of philosophical terms pertaining to science are not always consistent. However, this does not diminish the value of their collaboration and documentation of an inquiry process that extends from a statement of research goals to final publication of experimental research. Graves has demonstrated that the blending of data, theory, model, interpretation and rhetoric occurs with some degree of deliberation at every step. Regardless of the specific rhetorical theory one may subscribe to, and regardless of which kind of realist or non-realist philosophy one favors, it is clear that the practice of science involves tacit and fluctuating commitments to both. Nowhere is their oscillation more explicit than in chemistry's bimodal definition of element.

\section{Conclusion}

Metaphor is not merely linguistic; it can also be deployed as a conceptual strategy that disrupts fixation on any one of two or more explanatory frames that it brings together. In the latter capacity, it enables thought to get on with the important business of innovating something beyond the existing consensus on what, for example, is an element, whether basic or simple; what is bonding; structure; shape; etc. For example, Rom Harre has elaborated ${ }^{24}$ the concept of natural properties to express the notion of contingent, dispositional properties that are especially in evidence in the practice of chemistry.

The substance-attribute metaphysics immanent in the chemistry of the past must give way to metaphysics of spatially and temporally distributed causal powers to do justice to the way chemistry now appears. The language of the foundations of chemistry must be a language of tendencies and dispositions. [Harré 2010, 110]

Harré's examination of what he calls "chemical vernacular", as opposed to the specialized language of philosophers writing about chemistry, reveals a consistent reliance on causal power of particular agents. Harré calls for better alignment between the abstractions of the philosophy of chemistry and the concrete vernacular of chemical practice. Effective metaphors modify the behavior of chemists toward a given substance or reaction system by distributing attention among the several dispositional properties that pertain to a given experimental situation, depending on the instrumentation and observational conditions used. The late- $20^{\text {th }}$ century wave of science studies tend toward Pickering's idea that something like a "mangle of practice," the mutual resistance and accommodation of theory, instrumentation and practice, applies to all contemporary sciences. Over three and a half centuries ago,

24 Harré, R., 2010, Causal concepts in chemical vernaculars. Foundations of Chemistry 12:101-115 
chemistry emerged by acknowledging and wrestling with this dynamic interdependence to create a seemingly endless list of materials and processes. It should be no surprise then, given the role of metaphor in scientific creativity, that chemistry has been literally the most creative of the sciences.

References:

Aubusson, P., Harrison, A. G., \& Ritchie, S. (Eds.), 2006. Metaphor and analogy in science education (Vol. 30). Dordrecht: Springer.

Bailer-Jones, D. M., 2000, Scientific models as metaphors, in Hallyn, F., Metaphor and analogy in the sciences. Netherlands: Springer, 181-198.

Bailer-Jones, D. M., 2002, Models, metaphors and analogies, in Machamer, P., The Blackwell Guide to the Philosophy of Science. NY: Blackwell, 108-127.

Bensaude-Vincent, B., Stengers, I., 1996. A history of chemistry. Cambridge: Harvard University Press.

Black, M., 1962, Models and metaphors: Studies in language and philosophy. Ithaca: Cornell University Press.

Cartwright, N., 1983. How the laws of physics lie. Oxford: Clarendon Press.

Cassirer, E., 1953, Language and myth. NY: Dover Publications.

Dobbs, B. J. T., 2002. The Janus faces of genius: the role of alchemy in Newton's thought. Cambridge University Press.

Earley Sr., J.E., 2009, How chemistry shifts horizons: element, substance, and the essential. Foundations of Chemistry. 11, 65-77

Graves, H., 2005, Rhetoric In(to) Science: Style as Invention in Inquiry. NJ: Hampton Press.

Harré, R., 2010, Causal concepts in chemical vernaculars. Foundations of Chemistry 12:101-115.

Hacking, I., 1983, Representing and intervening. Cambridge: Cambridge University Press.

Jeppsson , F. , J. Haglund , T. G. Amin \& Helge Strmdahl, 2013, Exploring the Use of Conceptual Metaphors in Solving Problems on Entropy, Journal of the Learning Sciences, 22:1, 70-120.

Hesse, M.B.,1988, The cognitive claims of metaphor. The journal of speculative philosophy, 1-16.

Hesse, M.B., 1966, Models and analogies in science, Notre Dame, Indiana: Notre Dame University Press.

Hofmann, J. R. 1990. How the models of chemistry vie. In PSA: Proceedings of the Biennial Meeting of the Philosophy of Science Association (pp. 405-419). Philosophy of Science Association.

Kuhn, T. S., 1962. The structure of scientific revolutions. Chicago: University of Chicago press.

Kuhn, T. S., 1977, Second Thoughts on Paradigms, in Suppes, P., The structure of scientific theories. Urbana: University of Illinois Press, 459-483.

Kuhn, T. S., 1979, Metaphor in science, in Ortony, A., Metaphor and thought. Cambridge: Cambridge 
University Press, 533-542.

Lakoff, G., \& Johnson, M., 2008. Metaphors we live by. Chicago: University of Chicago Press.

Mahootian, F., 2013, Paneth's epistemology of chemical elements in light of Kant's Opus postumum. Foundations of Chemistry, 15(2), 171-184. Chicago: Springer.

Martin, J. and Harré, R., 1982, Metaphor in science, in D. S. Miall (ed.), Metaphor: Problems and Perspectives, Sussex: The Harvester Press, 89-105.

Merchant, C., 1980. The death of nature: women, ecology, and the scientific revolution. San Francisco: Harper Collins

Miller, A.I., 1984. Imagery in scientific thought creating 20th-century physics, NY: Springer-Verlag.

Miller, A. I., 1996. Insights of genius: Imagery and creativity in science and art. NY: Springer-Verlag.

Newman, W. R., \& Principe, L. M., 1998. Alchemy Vs. Chemistry: the Etymological Origins of a Historiographic Mistake1. Early Science and Medicine, 3(1), 32-65.

Nummedal, T. E., 2011. Words and Works in the History of Alchemy. Isis,102(2), 330-337.

Nye, M.J., 1994. From Chemical Philosophy to Theoretical Chemistry: Dynamics of Matter and Dynamics of Disciplines, 1800-1950. LA: University of California Press.

Paneth, F.A., 1962, The epistemological status of the chemical concept of element. Br. J. Philos. Sci. 13, 114, 144-160 (This was reprinted in Foundations of Chemistry, 5, 2003, 113-145. Kluwer, The Netherlands

Pickering, A., 1995. The mangle of practice: Time, agency, and science. Chicago: U. of Chicago Press.

Pickering, A., 1984. Constructing quarks: A sociological history of particle physics. Chicago: U. of Chicago

Ruthenberg, K.: 2009 Paneth, Kant, and the philosophy of chemistry. Foundations of Chemistry. 11, 79-91

Ricoeur, P., 1981. The rule of metaphor: Multi-disciplinary studies of the creation of meaning in language. Toronto: University of Toronto Press.

Scerri, E.R., 2000, Realism, reduction and the 'intermediate position'. In: Bhushan, N., Rosenfeld, S. (eds.) Of Minds and Molecules, pp. 51-72. NY: Oxford University Press,

Scerri, E.R., 2005. Some aspects of the metaphysics of chemistry and the nature of the elements. Hyle 11, 127-145

Scerri, E. R., 2009. The dual sense of the term "element," attempts to derive the Madelung rule, and the optimal form of the periodic table, if any. International Journal of Quantum Chemistry, 109(5), 959-971.

Tobin, K., \& Tippins, D. J. (1996). Metaphors as seeds for conceptual change and the improvement of science teaching. Science Education,80(6), 711-730.

Whitehead, A.N., 1938. Modes of thought, NY: McMillan Free Press.

Wu, K.-m., 2001. On Metaphoring: A Cultural Hermeneutic, Boston: Brill. 
